\title{
A Decrease in Antibiotic Utilization for Urinary Tract Infections in Women in Long-Term Care Facilities
}

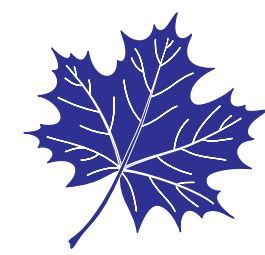

Fawziah Marra, BSc(Pharm), ACPR, PharmD, FSCHP ${ }^{1}$, Mark McCabe, $\mathrm{MPH}^{2}$, Abdullah Mamun, MBBS, MPH${ }^{3}$, David Patrick, MD, MHSc ${ }^{1,3}$

${ }^{1}$ Faculty of Medicine, The University of British Columbia |Vancouver Campus, Vancouver, BC, ${ }^{2}$ Public Health Agency of Canada, Ottawa, ON, ${ }^{3} B C$ Centre for Disease Control, Vancouver, BC

DOI: https://doi.org/10.5770/cgj.21.303

We have recently documented that antibiotic use in long-term care facilities (LTCF) in British Columbia is high 35 DDD per 1,000 residents per day. ${ }^{(1)}$ Upon further evaluation, we found that the decline in antibiotic use took place after 2012 and was steeper in women compared to men. Antibiotic prescriptions from January 1, 2007 to December 31, 2014 were extracted from PharmaNet, a centralized data system that contains information on all prescriptions dispensed from community pharmacies, for all "Plan B" or LTCF residents. Anonymous patient identifiers were used to match to the Medical Service Plan (MSP) billing system for indication (i.e., diagnostic codes based on the ninth revision of the International Classification of Diseases or ICD9). Long-term care population denominator values were estimated from the BC Ministry of Health Home and Community Care database that records each individual commencing or ending a stay at one of BC's LTCF. To calculate annual estimates, monthly cross-sections of all residents across LTCF in a given year were averaged. Defined daily dose (DDD) was used to calculate consumption rates as the number of defined daily doses consumed daily for every 1,000 long-term care residents.

In 2014, overall antibiotic use for urinary tract infection (UTI) was 6.58 DDD per 1,000 residents per day, with the majority of utilization being for treatment of cystitis and other disorders of the urethra and urinary tract (3.1 and 1.8 DDD per 1,000 residents per day, respectively). ${ }^{(1)}$ A gender breakdown of the 2014 data shows that the majority of the usage was in women at 7.17 DDD compared to men at 5.40 per 1,000 residents per day. The trend over time shows that 2012 was the peak year for antibiotic use in both gender groups and, since then, there has been a $25 \%$ reduction in usage in women (Figure 1). In Table 1 we can see the trends in specific UTI-related antibiotics over time for males and females. We see a significant decreasing trend in the use of ciprofloxacin and trimethoprim-sulfamethoxazole in females; although use has decreased in men as well, the trend was statistically insignificant. Nitrofurantoin use decreased in women, but remained steady in men. Interestingly, cefixime and amoxicillin-clavulanate usage have increased significantly in both groups, with an approximately $300 \%$ increase since 2007.

Numerous studies have shown overuse of antibiotics in long-term care facilities, particularly for UTI. ${ }^{(2-4)}$ With this in mind, many of BC's educational campaigns starting in 2012 have stressed the importance of adequate hydration, not using antibiotics in asymptomatic bacteriuria, as well as not necessarily jumping to a urine dipstick test for the stereotypical elderly person who has cloudy urine and delirium. ${ }^{(5,6)}$ Since there is no ICD9 code for asymptomatic bacteriuria, we were unable to assess actual antibiotic usage associated with it but, given that use in females has declined by $25 \%$ since 2012 (the start of the education program), we feel it is likely related to better stewardship by physicians and nurses in LTCF. Around 2012 was also the time when we started switching from ciprofloxacin and trimethoprimsulfamethoxazole as drugs of choice for UTIs to nitrofurantoin due to increasing E. coli resistance rates; ; $^{(7)}$ however, a simple switch in drug classes alone would not cause decline in total antibiotic usage for UTIs. In fact, the decrease in overall antibiotic use is along the same magnitude as the decline seen in women $(\sim 21 \%)$.

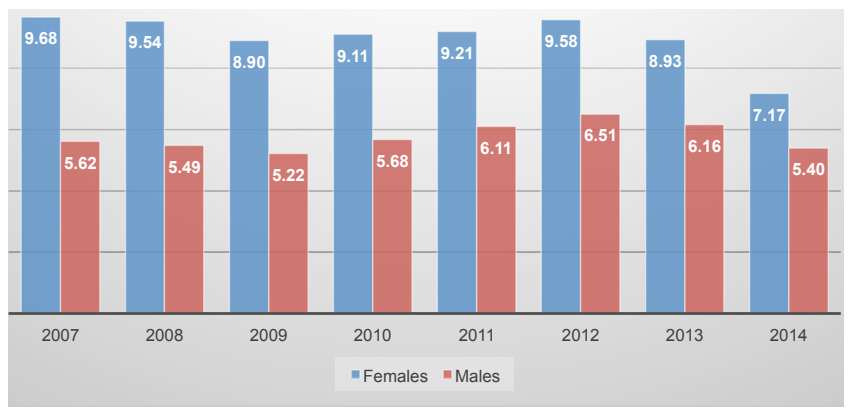

FIGURE 1. Antibiotic use for urinary tract infections by gender, 2007 to 2014. Usage is in DDD per 1000 residents per day. 
TABLE 1.

Common antibiotics used for urinary tract infections by gender, 2007 to 2014

\begin{tabular}{|c|c|c|c|c|c|c|c|c|c|c|c|}
\hline & 2007 & 2008 & 2009 & 2010 & 2011 & 2012 & 2013 & 2014 & $\%$ change & $\begin{array}{l}\text { Spearman } \\
\text { Correlation }\end{array}$ & p-value \\
\hline Overall (J01) & 8.41 & 8.28 & 7.74 & 8.02 & 8.21 & 8.58 & 8.02 & 6.58 & -21.72 & -0.31 & 0.46 \\
\hline Females & 9.68 & 9.54 & 8.90 & 9.11 & 9.21 & 9.58 & 8.93 & 7.17 & -25.84 & -0.57 & 0.15 \\
\hline Males & 5.62 & 5.49 & 5.22 & 5.68 & 6.11 & 6.51 & 6.16 & 5.40 & 3.77 & 0.33 & 0.43 \\
\hline \multicolumn{12}{|l|}{ Nitrofurantoin } \\
\hline Females & 3.53 & 3.50 & 3.14 & 3.43 & 3.60 & 3.68 & 3.34 & 2.47 & -30.07 & -0.28 & 0.50 \\
\hline Males & 1.37 & 1.24 & 1.26 & 1.47 & 1.52 & 1.73 & 1.68 & 1.35 & -1.99 & -0.50 & 0.21 \\
\hline \multicolumn{12}{|l|}{ Ciprofloxacin } \\
\hline Females & 2.20 & 2.15 & 2.08 & 1.89 & 1.91 & 1.83 & 1.49 & 1.24 & -43.68 & -0.97 & 0.001 \\
\hline Males & 1.76 & 1.77 & 1.67 & 1.73 & 1.74 & 1.80 & 1.58 & 1.29 & -26.82 & -0.52 & 0.20 \\
\hline \multicolumn{12}{|c|}{$\begin{array}{l}\text { Sulfamethoxazole and } \\
\text { trimethoprim }\end{array}$} \\
\hline Females & 1.80 & 1.63 & 1.49 & 1.49 & 1.37 & 1.25 & 1.35 & 1.10 & -38.77 & -0.95 & 0.001 \\
\hline Males & 0.98 & 1.12 & 0.92 & 1.00 & 1.04 & 1.05 & 0.89 & 0.91 & -6.51 & -0.42 & 0.29 \\
\hline \multicolumn{12}{|l|}{ Cefixime } \\
\hline Females & 0.11 & 0.12 & 0.14 & 0.26 & 0.33 & 0.48 & 0.52 & 0.27 & 139.26 & 0.85 & 0.01 \\
\hline Males & 0.06 & 0.07 & 0.07 & 0.13 & 0.25 & 0.33 & 0.35 & 0.22 & 265.39 & 0.85 & 0.01 \\
\hline \multicolumn{12}{|c|}{ Amoxicillin clavulanate } \\
\hline Females & 0.07 & 0.08 & 0.11 & 0.16 & 0.24 & 0.29 & 0.30 & 0.30 & 318.41 & 0.99 & 0.001 \\
\hline Males & 0.08 & 0.10 & 0.08 & 0.11 & 0.20 & 0.22 & 0.25 & 0.30 & 260.66 & 0.92 & 0.002 \\
\hline
\end{tabular}

Implementing antimicrobial stewardship is more challenging in non-hospital environments than in a closed system such as hospital wards, and even more so at the population level. Despite this, the availability of guidelines on collection of urine, consistency of messaging, and education of all clinicians seems to have made a difference in antimicrobial prescription rates for UTIs in long-term care facilities. We need to continue our messaging around when antibiotics should be prescribed, as well as addressing the increasing use of cefixime and amoxicillin-clavulante.

\section{Copyright}

Published under the CreativeCommons Attribution-Non Commercial-NoDerivs 3.0 License.

\section{REFERENCES}

1. Marra F, McCabe M, Sharma P, et al. Utilization of antibiotics in long term care facilities in British Columbia, Canada. $J \mathrm{Am}$ Med Dir Assoc. 2017;18(12):1098.

2. van Buul LW, Veenhuizen RB, Achterberg WP, et al. Antibiotic prescribing in Dutch nursing homes: how appropriate is it? $J$ Am Med Dir Assoc. 2015;16(3):229-37.

3. Phillips CD, Adepoju O, Stone N, et al. Asymptomatic bacteriuria, antibiotic use, and suspected urinary tract infections in four nursing homes. BMC Geriatr. 2012;12(1):73.
4. Loeb M, Simor AE, Landry L, et al. Antibiotic use in Ontario facilities that provide chronic care. J Gen Intern Med. 2001;16(6):376-83.

5. Providence Healthcare. Antimicrobial Stewardship Program Annual Report 2015-2016 [Internet]. Vancouver, BC: Providence Healthcare; 2016. Available from: http://www.providencehealth care.org/sites/default/files/AMS\%20Providence\%20Annual $\% 20$ Report\%202016.pdf

6. Government of British Columbia. Provincial Academic Detailing Service. UTIs in primary and long term care [Internet]. Vancouver, BC: BC Government; 2017. Accessed on 2017 Jan 23. Available from: http://www2.gov.bc.ca/gov/content/health/ practitioner-professional-resources/pad-service/utis-in-primaryand-long-term-care

7. BC Centre for Disease Control. Antimicrobial surveillance tools. Antimicrobial resistance. [Internet]. Vancouver, BC: The Centre; 2016. Available from: http://www.bccdc.ca/ health-professionals/data-reports/antimicrobial-resistance/ antimicrobial-resistance-dashboard

Corresponding author: Fawziah Marra, BSc(Pharm), ACPR, PharmD, FSCHP, Faculty of Pharmaceutical Sciences, The University of British Columbia | Vancouver Campus, 2405 Wesbrook Mall, Vancouver, BC Canada V6T 1 Z3

E-mail: fawziah.lalji@ubc.ca 